УДК 331.104.22 JEL M12

Дьяконова Мария Александровна канд. полит. наук, ФГБОУ ВО «Государственный университет управления», г. Москва e-mail:marie.d@mail.ru

Шарипов Фанис Фалихович канд. эконом. наук, ФГБОУ ВО «Государственный университет управления», г. Москва e-mail:fanissh@rambler.ru

\section{Dyakonova Maria}

Candidate of Political Sciences, State University of Management, Moscow e-mail: marie.d@mail.ru

\section{Sharipov Fanis}

Candidate of Economic Sciences, State University of Management, Moscow e-mail:fanissh@rambler.ru

\section{ЭВОЛЮЦИЯ ПОНЯТИЯ «УПРАВЛЕНИЕ ЧЕЛОВЕЧЕСКИМИ РЕСУРСАМИ»}

\begin{abstract}
Аннотация. Рассмотрена эволючия такого понятия, как человеческие ресурсы, даны варианты определения этого понятия отечественными и иностранными учеными. Обоснована актуальность теории управления человеческими ресурсами и возможности ее применения в практическом управлении организацией. Определены основные проблемы управления человеческими ресурсами. Первостепенной задачей для практиков в области управления человеческими ресурсами на современном этапе экономического развития признано внедрение новых форм и методов организации трудовой деятельности, которые будут способствовать максимально полному раскрытию потенциальных возможностей человека. Исследование актуально для наставников, занятых непосредственной подготовкой специилистов в области международного бизнеса.
\end{abstract}

Ключевые слова: международное деловое сотрудничество, управление человеческими ресурсами, интеллектуальный капитал, инновачионные методы управления, новые формы и методы организации труда, международный бизнес.

\section{EVOLUTION OF CONCEPT OF «HUMAN RESOURCE MANAGEMENT»}

\begin{abstract}
The evolution of such concept as human resources, and its definitions given by domestic and foreign scientists are considered. The relevance of the theory of human resource management and possibilities of its application in practical management of an organization is proved. Main problems of human resource management are defined. A priority objective for practitioners in the field of human resource management at the current stage of economic development is the introduction of new forms and methods of work organization which will contribute to the maximum disclosure of potential human capabilities. This is a topical subject for the coaches who train specialists in the field of international business.

Keywords: international business cooperation, human resource management, intellectual capital, innovative methods of management, new forms and methods of organization of work, international business.
\end{abstract}

В современном быстроразвивающемся мире появляется все больше способов и методов ведения международного делового сотрудничества. Деловое взаимодействие между странами происходит в основном на экономическом, политическом, научном и культурном уровнях. Взаимовыгодное сотрудничество проводится как на двусторонней основе с разными странами, так и в рамках различных организаций. Управление человеческими ресурсами - сложный и актуальный процесс любой организации, стремящейся занимать лидирующие позиции на рынке. Правильное управление позволит привлекать инвестиции в организацию, экономически развиваться и вести деятельность в условиях международного взаимодействия.

В конце 80-х годов прошлого века исследователи предложили четыре отличительные стратегические цели нового понятия «управление человеческими ресурсами», отталкиваясь от традиционного понятия «управление персоналом» [12]. Обозначим их.

1. Необходимо поощрять приверженность сотрудников своему делу, чтобы увеличить их работоспособность, а также быть лояльными к своей организации в целом.

2. Необходимо делать акценты на качестве работы сотрудников, занятых в организации, так как это имеет большое значение для производства качественных товаров и услуг, что выгодно как для клиентов, так и для самой организации.

3. Необходимо обеспечить гибкий график при организации работы сотрудников, так как это помогает работникам легче адаптироваться и воспринимать любые изменения во всех сферах, включая рабочие часы, методы работы и прочее.

4. Необходимо интегрировать организационные цели в стратегическое планирование, чтобы эта политика не шла вразрез с рядовыми членами организации и гарантировала им каждодневную работу под руководством линейных менеджеров. 
Беспокойство относительно благосостояния сотрудников в организациях наибольшую актуальность приобрело в 1990-х гг., чтобы заставить сотрудников увеличить их приверженность делу в организации, а также увеличить уровень их удовлетворенности работой [12]. Теории гуманизма, кооперации и марксизма начала 1900-х гг. выдвинули на первый план потенциальные конфликты между интересами сотрудника и работодателя в промышленности. Это стало началом роста профсоюзного движения и развития системы новых отношений между предпринимателями и рабочими, которые являются важными элементами современного управления человеческими ресурсами [14]. Понятие «управление человеческими ресурсами» (Human Resource Management) появилось относительно недавно на Западе и заняло достойное место в управленческой среде всех стран [15].

Рассмотрим определение понятия «человеческие ресурсы». В иностранном бизнес-словаре приводится следующее определение: человеческие ресурсы - это подразделение организации, которое фокусируется на деятельности, связанной с работниками. Эта деятельность включает поиск и прием на работу новых сотрудников, координирование и подготовку работающих кадров, дополнительные выплаты и льготы работникам, удержание сотрудников на рабочих местах. Ранее использовался термин «кадры». «Нuman Resource is the division of a company that is focused on activities relating to employees. These activities normally include recruiting and hiring of new employees, orientation and training of current employees, employee benefits, and retention. Formerly called personnel» [14].

В отечественной литературе используют более широкое понятие: человеческие ресурсы - это ресурсы организации, т. е. подразумевают основные ресурсы, используемые организацией. Это люди (человеческие ресурсы), капитал, материалы, технология и информация [6]. И более конкретно: человеческие ресурсы это совокупность количества людей (людские ресурсы) и человеческого потенциала (опыта, компетенций, интеллекта, способности к постоянному совершенствованию и развитию); человеческий потенциал, который необходимо мотивировать и развивать, чтобы достичь стратегических целей организации [6; 7].

Представляется интересным определение этого понятия одним из наиболее известных теоретиков и практиков по управлению человеческими ресурсами - Майкла Армстронга [10]. Майкл Армстронг выделяет управление человеческими ресурсами как стратегический и последовательный подход к управлению самыми ценными активами организации - людьми, работающими в этой организации, которые индивидуально и коллективно вносят вклад в достижение ее целей [8].

Управление человеческими ресурсами также касается трудовых отношений, т. е. баланс организационных методов с инструкциями, являющимися результатом коллективных переговоров и государственных законов [9]. Управление человеческими ресурсами состоит из всех видов деятельности, предпринимаемых организацией для эффективного использования трудовых ресурсов в достижении личных, групповых и организационных целей. Функция управления человеческими ресурсами организации направлена на человеческий аспект управления.

Таким образом, управление человеческими ресурсами - продукт движения человеческих отношений начала двадцатого века, когда исследователи начали разрабатывать новые виды документов, чтобы создать ценность бизнеса благодаря стратегическому управлению трудовыми ресурсами. Функция первоначально доминировала в деловой деятельности, такой как регулирование платежных ведомостей и льгот, но из-за глобализации, консолидации компаний, технологического прогресса и дальнейшего исследования, управление человеческими ресурсами теперь фокусируется на таких стратегических инициативах, как слияние и поглощение организаций, управление талантами, непрерывное планирование, производственные и трудовые отношения, этические аспекты, разнохарактерность экономической деятельности. Все это, среди других инициатив, способствует пониманию управления человеческими ресурсами как современной проблемы вследствие длительного эволюционного характера [13].

Так как люди - один из наиболее непредсказуемых и разнообразных ресурсов, то найти правильный подход к управлению ими - очень сложный процесс. Для достижения успеха в этом процессе требуются неординарные решения и методы ведения деятельности, вплоть до индивидуального подхода к каждому сотруднику. В современном конкурентоспособном и активном мире управление человеческими ресурсами является своего рода проблемой. Поэтому и подходы к управлению человеческими ресурсами должны быть актуальными и соответствующими вопросу.

Таким образом, центр управления человеческими ресурсами сегодня фокусируется на эффективном управлении трудовыми ресурсами организации, чтобы способствовать достижению желаемых целей и вершин. Все процессы управления человеческими ресурсами (например, поиск, переманивание, развитие, проверка 
качества работы, система вознаграждений), как отмечается, являются интегрированными компонентами стратегий управления человеческими ресурсами. Основным принципом является, конечно, эффективное использование знаний, умений и навыков сотрудников для достижения организационных целей [11].

В современных организациях акцент может быть сделан больше на «интеллектуальном капитале», «работнике умственного труда», или на «эмоциональном восприятии», чем на физических умениях и навыках. Эти проблемы являются неотъемлемой частью управления современным «работником умственного труда» и будут продолжать формировать теорию и практику управления человеческим ресурсами, продвигаясь вперед [11]. При этом останется основная проблема, связанная с так называемой «утечкой умов».

Различия теорий управления человеческими ресурсами подчеркивают разные аспекты управления трудовыми отношениями, отражающие разнообразие национальной или промышленной окружающей среды [11]. То есть человеческие ресурсы определяются уникальной способностью развиваться, самообразовываться, а также и самосовершенствоваться [1]. Следовательно, формирование климата, внедрение форм и методов в организации, как ресурса, и формирование у него новых профессиональных компетенций, которые будут способствовать максимально полному раскрытию потенциальных возможностей человека, является первостепенной задачей для практиков в области управления человеческими ресурсами на современном этапе экономического развития [4].

Глобальный экономический рост, который неизбежно последует после кризиса и спада, создаст условия для выхода на новый уровень конкуренции за человеческие ресурсы. Увлечение, вовлечение, развитие, а также использование инноваций - ключевые направления в работе с людьми [3].

Справедливо будет сказать, что управление человеческими ресурсами - это совмещение искусства и науки, поскольку грамотное управление людьми является искусством руководить с помощью творческого и инновационного подхода; но этот подход должен быть научным, так как теория, которая требуется, должна быть верной и точной [2].

Итак, более века управление человеческими ресурсами, как дисциплина в сфере управления людьми в организации, изменялась и развивалась в различных областях. Все дисциплины и исследования прошли процесс поиска новых и более успешных методов решения данной проблемы, теорий построения и проверки различных концептов, обучая специалистов в сфере управления и исследователей. Все изученное во время эволюции и развития управления человеческих ресурсов было, и остается, главным вопросом и запросом для обретения знаний по улучшению трудовой деятельности.

Современные теории управления человеческими ресурсами также признают, что человеческие ресурсы, в отличие от финансовых или технологических, нельзя «эксплуатировать», и что они требуют сложного и чувствительного управления, чтобы полностью реализовать свой потенциал $[9 ; 10 ; 11]$.

\section{Библиографический список}

1. Абрамов, Е. Г. Оценка и управление формированием интеллектуальных активов наукоемких организаций: монография / Е. Г. Абрамов. - М.: Креативная экономика, 2010. - 172 с.

2. Бурматнова, О. В. Особенности управления человеческими ресурсами в современных условиях российской экономики / О. В. Бурматнова, Ю. В. Зайцева, А. Н. Максаков, О. В. Старостина, Е. Г. Черепанова [Электронный ресурс]. - Режим доступа: http://law-journal.ru/files/pdf/201509/201509_117.pdf (дата обращения: 30.03.2018).

3. Масалова, Ю. А. Качество человеческих ресурсов как объект управления в системе высшего образования / Ю. А. Масалова // Известия Иркутской государственной экономической академии. - 2016. - Т. 26. - № 1. - С. 107-114.

4. Чекан, А. А. Основные тенденции в управлении персоналом: прогнозы и реалии / А. А. Чекан, Л. В. Матюнин // Вестник Московского государственного областного университета. Серия: Экономика. - 2017. - № 2. - С. 162-168.

5. Использование человеческих ресурсов [Электронный ресурс]. - Режим доступа: https://dic.academic.ru/dic.nsf/ruwiki/99414 (дата обращения: 30.03.2018).

6. Ресурсы организации [Электронный ресурс]. - Режим доступа: https://big_economic_dictionary.academic.ru/13143/\%D0 \%A0\%D0\%95\%D0\%A1\%D0\%A3\%D0\%A0\%D0\%A1\%D0\%AB_\%D0\%9E\%D0\%A0\%D0\%93\%D0\%90\%D0\%9D\%D0\%9 $8 \% \mathrm{D} 0 \% 97 \% \mathrm{D} 0 \% 90 \% \mathrm{D} 0 \% \mathrm{~A} 6 \% \mathrm{D} 0 \% 98 \% \mathrm{D} 0 \% 98$ (дата обращения: 30.03.2018).

7. Управление человеческими ресурсами, [Электронный ресурс]. - Режим доступа: http://acmegroup.ru/node/144 (дата обращения: 30.03.2018). 
8. Armstrong, M. A Handbook of human resource management practice / M. Armstrong // Kogan Page, London. $-2006 .-10^{\text {th }}$ ed. - p. 982.

9. Johnson, P. Human resource management: a critical approach. HRM in changing organizational contexts / P. Johnson // London: Routledge. - 2009. - p. 19-37.

10. Michael Armstrong [Электронный ресурс]. - Режим доступа: https://www.koganpage.com/author/michael-armstrong\# (дата обращения: 30.03.2018).

11. Nankervis et.al. Human resource management: strategy and practice / Nankervis et. al. // Cencage Learning, Melbourne, Australia. $-2011 .-7$ th ed. - p. 44.

12. Osibanjo, O. Human resource management: theory and practice [Электронный pecypc] / O. Osibanjo, A. Adenike Adeniji Режим доступа: https://www.researchgate.net/publication/305954894_Human_Resource_Management_Theory_and_Practice (дата обращения: 30.03.2018).

13. Tubey, R. History, evolution and development of human resource management: A Contemporary Perspective / R. Tubey, K. J. Rotich, A. Kurgat // European Journal of Business and Management. - 2015. - Vol. 7. - I. 9. - pp. 139-148.

14. Human resources [Электронный ресурс]. - Режим доступа: http://www.businessdictionary.com/definition/human-resources. html (дата обращения: 30.03.2018).

15. The historical background of human resource management [Электронный ресурс]. - Режим доступа: http://www.whatishumanresource.com/the-historical-background-of-human-resource-management (дата обращения: 30.03.2018).

\section{References}

1. Abramov E. G. Ocenka i upravlenie formirovaniem intellektual'nyh aktivov naukoemkih organizacij: monografija [Valuation and management of formation of intellectual actives of knowledge-based organizations : monograph]. M.: Kreativnaja jekonomika, 2010. - p. 172.

2. Masalova Ju. A. Kachestvo chelovecheskih resursov kak ob'ekt upravlenija v sisteme vysshego obrazovanija [Human resources quality as an object of management in higher education system]. Izvestija Irkutskoj gosudarstvennoj jekonomicheskoj akademii [News of Irkutsk state economic academy], 2016, T. 26, I. 1, pp. 107-114.

3. Chekan A. A., Matjunin L. V. Osnovnye tendencii v upravlenii personalom: prognozy i realii [Trends of personnel management : forecasts and realities]. Vestnik Moskovskogo gosudarstvennogo oblastnogo universiteta. Serija: Jekonomika [Moscow state district university's herald], 2017, I. 2, pp. 162-168.

4. Burmatnova O. V., Zajceva Ju. V., Maksakov A. N., Starostina O. V., Cherepanova E. G. Osobennosti upravlenija chelovecheskimi resursami v sovremennyh uslovijah rossijskoj jekonomiki [Features of human resource management in modern Russian economy] / O. V. Burmatnova, Ju. V. Zajceva, A. N. Maksakov, O. V. Starostina, E. G. Cherepanova Available at: http://law-journal. ru/files/pdf/201509/201509_117.pdf (accessed 30.03.2018).

5. Ispol'zovanie chelovecheskih resursov [Use of human resources]. Available at: https://dic.academic.ru/dic.nsf/ruwiki/99414 (accessed 30.03.2018).

6. Resursy organizacii [Organizational resources]. Available at: https://big_economic_dictionary.academic.ru/13143/\%D0\%A0\% D0\%95\%D0\%A1\%D0\%A3\%D0\%A0\%D0\%A1\%D0\%AB_\%D0\%9E\%D0\%A0\%D0\%93\%D0\%90\%D0\%9D\%D0\%98\%D0\% 97\%D0\%90\%D0\%A6\%D0\%98\%D0\%98 (accessed 30.03.2018).

7. Upravlenie chelovecheskimi resursami [Human resource management]. - Available at: http://acmegroup.ru/node/144 (accessed 30.03.2018).

8. Armstrong, M. A Handbook of human resource management practice / M. Armstrong // Kogan Page, London, 2006, 10 $0^{\text {th }}$ ed, p. 982.

9. Tubey, R. History, evolution and development of human resource management: a contemporary perspective / Dr. R. Tubey, K. J. Rotich, Dr. A. Kurgat // European journal of business and management, 2015, Vol. 7, I. 9, pp. 139-148.

10. Human resources. Available at: http://www.businessdictionary.com/definition/human-resources.html (accessed 30.03.2018).

11. Johnson, P. Human resource management: a critical approach. HRM in changing organizational contexts / P. Johnson // London: Routledge, 2009, pp. 19-37.

12. Michael Armstrong. Available at: https://www.koganpage.com/author/michael-armstrong\# (accessed 30.03.2018).

13. Nankervis et.al. Human resource management: strategy and practice / Nankervis et.al // Cencage Learning, Melbourne, Australia, $2011,7^{\text {th }}$ ed, p. 44.

14. Osibanjo, O. Human resource management: theory and practice / O. Osibanjo, A. Adenike Adeniji - Available at: https://www. researchgate.net/publication/305954894_Human_Resource_Management_Theory_and_Practice (accessed 30.03.2018).

15. The historical background of human resource management. - Available at: http://www.whatishumanresource.com/the-historical-background-of-human-resource-management (accessed 30.03.2018). 